\title{
A Study of the Influence of Aerodynamic Loads on the Forces Exchanged in a Twistlock Corner Casting Connection of Flat-Wagons
}

\author{
E. Di Gialleonardo, S. Melzi, F. Resta and G. Tomasini \\ Dipartimento di Meccanica \\ Politecnico di Milano \\ Italy
}

\begin{abstract}
In this paper cross-wind effects on freight wagons are studied. A mathematical model of a freight train made up of a flat-car and one or two containers has been built defining the dynamical characteristics of the connection (twistlock-corner casting). Wind tunnel tests on a scaled model are then used to define the aerodynamic coefficients of the wagon, both in loaded and unloaded conditions, considering different trainset layouts. Wind forces are finally applied separately to the container and the flat-car in order to define the CWC of the wagon and to verify the maximum forces exchanged through the twistlock-corner casting connection. The results of the analysis showed that severe conditions with respect to the risk of rollover can be found as a result of a succession of empty and loaded wagons.
\end{abstract}

Keywords: rollover, critical wind curves, freight trains, modelling, twistlock.

\section{Introduction}

Aerodynamics of railway vehicles plays an important role both for economic and safety reasons. The aerodynamic forces are the main contribution to the running resistance of the vehicle as far as the speed is sufficiently large but they can also affect the safety of the railway vehicles, increasing the overturning risk. These effects can become critical if associated with a large speed of the vehicle or with scenarios where sudden changes of the aerodynamic forces can occur (i.e. the exit of a tunnel, the negotiation of a curve, etc.).

Several studies are present in literature $[1,2]$ analysing the aerodynamics of highspeed trains for passenger transportation. For these reasons the shape of the bodies was optimized to minimize drag and the effect of crosswind on stability and rollover risk. On the contrary, very few studies have been performed on the aerodynamics of freight trains. 
In recent years, environmental concerns and cost savings opportunities (at least for long-medium distances), moved the interest towards goods transportation operated with freight trains. Reducing transportation time appears nowadays as a key factor to gain competitiveness against road transportation. For this reason, freight trains speed is being continuously increased so that the travel time on long and medium distances could be comparable at least to that of ordinary passenger trains.

Speed increase of freight trains can have several impacts on running safety, also related to their aerodynamic response. In fact, even with travelling speeds below 200 $\mathrm{km} / \mathrm{h}$ (thus well below the one reached by a high-speed passenger train), typical features of freight trains can remarkably worsen the effects of interaction with wind. As first, aerodynamic performances of freight trains are quite poor: vehicle and/or payload are characterized by wide, squared surfaces that lead to high aerodynamic coefficients. In addition, vehicles of freight trains are not in fixed composition: a significant gap between adjacent vehicles is present and, especially when flatwagons are considered, empty vehicles alternate with loaded ones. In all the cases, unlike passenger trains, the front section of a vehicle is directly exposed to wind. Additionally, freight wagons may experience a large variation of the axle from tare to full load conditions, since the payload provides the main contribution to the total weight.

This work was carried out inside SIFEG, a project funded by the Italian Ministry of Economic Development (MISE) with the aim of improving efficiency of goods transportation. Part of the project is related with the design of a freight vehicle for intermodal transport (a flat-wagon) able to operate at a speed of $160 \mathrm{~km} / \mathrm{h}$. Considering the possible effects of crosswind on rollover risk for both vehicle and container [3], an exhaustive analysis was carried out.

The aim of the work is to highlight the worst compositions in terms of rollover risk, taking also into account the interaction between the flat-wagon and the container, provided by the twistlock - corner casting connection.

As first step, a mathematical model of the vehicle accounting for the peculiarities of the twistlock - corner casting connection was built, then wind tunnel tests were performed to measure the aerodynamic forces on both the flat-wagon and the container considering different train-set compositions [4]

Data obtained during this research phase were then used as in-put for a numerical model $[5,2]$ allowing to investigate the interaction between the wagon and the turbulent wind. Finally, Characteristics Wind Curves for the wagon are identified for the most critical train-set compositions verifying the forces exchanged through the connection of the container to the flat-wagon.

\section{Mathematical model of the freight wagon}

\subsection{Multi-body schematisation of the wagon}

The multi-body model of the vehicle is based on a rigid body schematisation of the freight wagon. In particular, three different modules are used and connected by means of suspension elements in order to reproduce the architecture of the vehicle: 
1) a container, whose size can be $20 \mathrm{ft}$ or $40 \mathrm{ft}$, depending on the layout considered;

2) a flat-wagon;

3) a bogie assembly which consists of a bogie frame connected to two wheelsets by means of the primary suspensions.

Module (1) is connected to module (2) by means of nonlinear elastic elements modelling the nonlinear behaviour of the twistlock - corner casting connection, which will be described in details in the following subsection. Module (2) is connected to two modules (3) by means of a secondary suspension, having the typical arrangement of railway vehicles for passenger transportation.

The equations of motion of the complete wagon are obtained neglecting the longitudinal dynamics, thus assuming a constant speed forward motion and, additionally, small displacements and rotations of the module with respect to moving reference frames. Each module is associated with a moving reference frame having the same longitudinal position of the centre of gravity of the bodies.

Wheel-rail contact model is based on a multi-Hertzian schematisation of the contact patch [6, 7] while heuristic formulae by Shen, Hedrick and Elkins [8] are used in order to solve the tangential problem.

Considering the range of frequency of interest in this problem $(<20 \mathrm{~Hz})$, a rigid track assumption is made, without compromising the validity of the model, as explained in details in [9].

The equations of motion of the system can be written in a matrix form as follows:

$$
\left[M_{v}\right] \underline{\ddot{x}}_{v}+\left[C_{v}\right] \underline{\dot{x}}_{v}+\left[K_{v}\right] \underline{x}_{v}=\underline{F}_{n l}\left(\underline{x}_{v}, \underline{\dot{x}}_{v}, V, t\right)+\underline{F}_{a e r}(V, t)
$$

being $\underline{x}_{v}$ the vector of the vehicle independent coordinates, $\left[M_{v}\right],\left[C_{v}\right]$ and $\left[K_{v}\right]$ the mass, damping and stiffness matrices respectively, $F_{n l}$ the Lagrangian components on the vehicle coordinates of the nonlinear forces, such as the contact forces and the forces exchanged through the twistlock - corner casting connection, while $F_{a e r}$ represent the effect of the aerodynamic forces, which are obtained as it will be explained more in details in Section 3.

The equations are finally solved using a numerical procedure based on Newmark $\beta$-method.

\subsection{Modelling of the twistlock - corner casting connection}

The ensemble of a twist-lock and a corner casting is the most common way to secure container both over other containers or directly on flat-wagons.

The connection is made up of two parts, one representing the male connector (twistlock) and the other one the female connector (corner casting). The corner casting is directly fitted to the container and has an oval hole in the bottom while the twistlock is fitted to the flat-wagon.

Figure 1 shows a scheme of the connection in the two possible conditions: unlocked (on the left) and locked (on the right). 

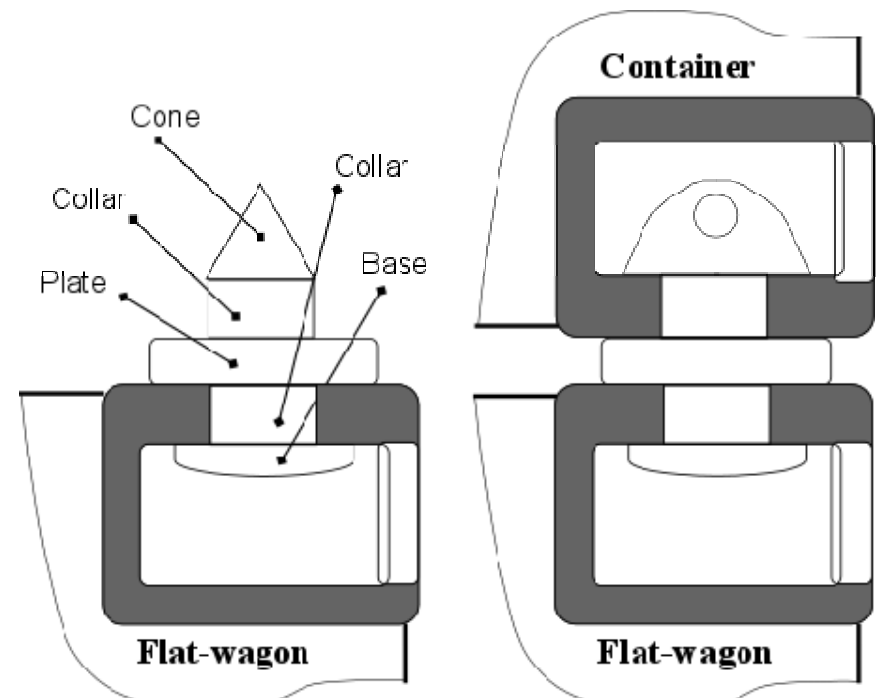

Figure 1: Scheme of the twistlock - corner casting connection.

In order to secure the connection, the twistlock is inserted through the hole and then its top portion is rotated by $90^{\circ}$.

The lower side of the corner casting is placed over the intermediate plate of the twistlock, the cone is then inserted through the hole and then is rotated $90^{\circ}$ so it cannot be withdrawn. The compression loads are sustained by the plate, the traction loads by the cone and the base of the twistlock, while the collars sustain shear forces.

Standard ISO 3874/1 [10] prescribes the maximum forces that can be applied to the twist-lock without compromising their functionality. The limit values imposed by the standard are reported in Table 1 .

\begin{tabular}{|l|l|}
\hline Traction force & $150 \mathrm{kN}$ \\
\hline Compression force & $850 \mathrm{kN}$ \\
\hline Shear force & $300 \mathrm{kN}$ \\
\hline
\end{tabular}

Table 1: Limit force values imposed by ISO 3874/1 [10].

The traction and shear force limits are the most binding. The static values for this forces are ideally zero, thus the limit is directly related to the dynamic value. With regard to the compression force, on the contrary, a fully laden container generates a compression force of around $300 \mathrm{kN}$, thus reducing to $550 \mathrm{kN}$ the limit on the dynamic value of the force, which, however, is far larger with respect to the others. In case of severe wind, the roll moment acting on the container can generate large traction forces which can eventually deform in a permanent way the twistlock.

A finite element model of the twistlock - corner casting assembly (Figure 2) is set-up in order to define the characteristics of the connection in terms of forcedeflection curves for each direction. This will permit to calculate the forces exchanged between the elements and eventually verify their resistance, even in critical crosswind conditions. The components are supposed to be made by $\mathrm{C} 45$ steel. This material has an elastic modulus equal to $210000 \mathrm{MPa}$, a Poisson 
coefficient of 0.3 and a yield strength equal to $310 \mathrm{MPa}$. The simulations are performed taking into account that the bodies can interact only when penetration between them is detected, without imposing any kinematical constraint. The contact condition also permits to exchange tangential forces due to friction between the surfaces.
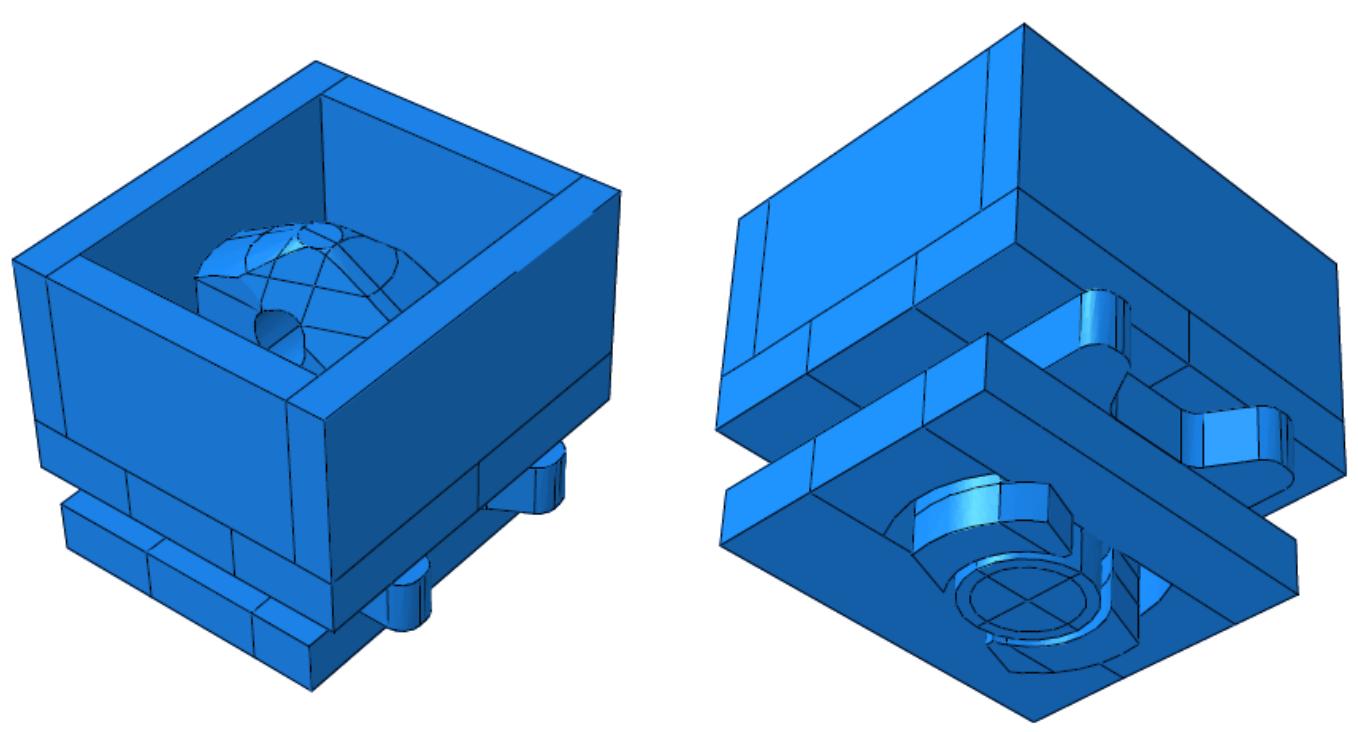

Figure 2: Finite element model of the twistlock - corner casting connection.

Four different tests were carried out in order to define the nonlinear behaviour of the twistlock - corner casting connection. The traction and compression tests permits to define the global stiffness of the ensemble in vertical direction, whereas two different shear tests are used to define the force-deflection curve in lateral and longitudinal directions. In the following, for the sake of brevity, only the traction test is analysed more into details.

The load is applied by means of a fixed plate and a loading structure having the same geometry as the corner casting.

Figure 3 shows a vertical section of the model when the maximum load is applied (equal to $150 \mathrm{kN}$, according to ISO 3874/1). For this test, the lower surface of the base plate has been constrained by means of an ideal clamp to the ground, while the traction load has been uniformly distributed on the upper surface of the corner casting. It is observed that the FE model highlights the contact between the base of the cone of the twistlock and the inner surface of the corner casting. Additionally, it is shown that the twistlock interacts with the base plate deforming it. For the case under analysis, the maximum Von Mises stresses are around $250 \mathrm{MPa}$, well below the yield strength of the material.

The test was performed gradually increasing the load from 0 up to $150 \mathrm{kN}$, in order to derive the stiffness of the ensemble as a function of the load. It is found that the relationship between force and deflection is essentially linear in this range and the stiffness is equal to $7700 \mathrm{kN} / \mathrm{mm}$. 

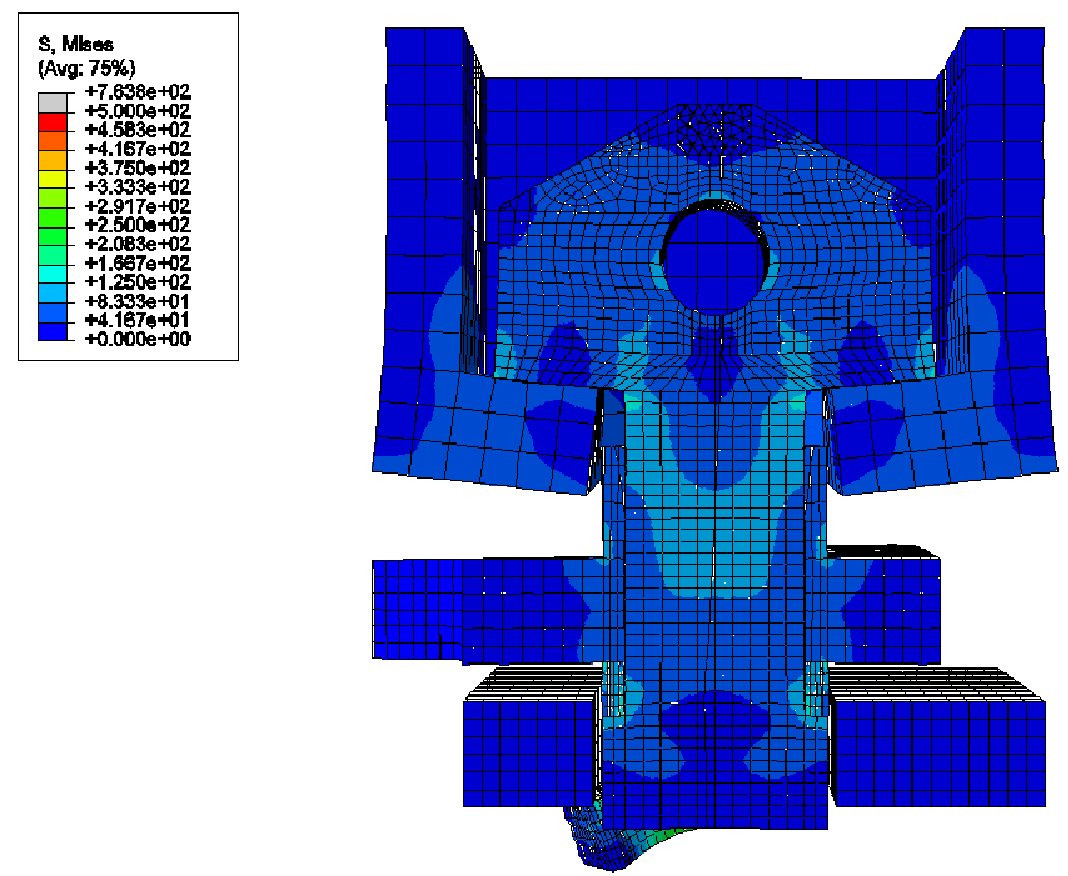

Figure 3: Stress field on a vertical section of the twistlock - corner casting connection.

The results in terms of force-deflection curves for the three directions are reported in Figure 4.

Apart from the clearances that are present in each direction, it is clearly visible that a nonlinear behaviour is found for the stiffness of the ensemble in the horizontal plane. This is mainly due to the fact that as far as the load increases the geometry of the contact between the collars and the corresponding lateral surfaces changes. Essentially the larger the load the larger the contact surface and, thus, the resulting stiffness.
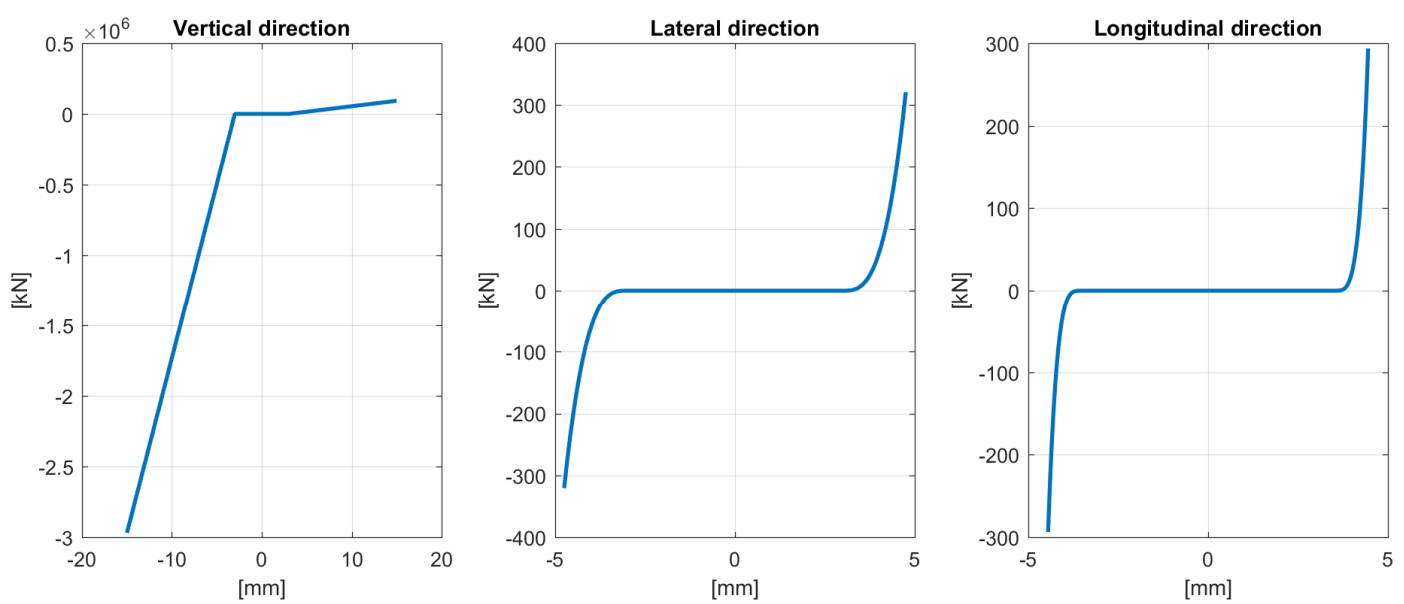

Figure 4: Force - deflection curves of the twistlock - corner casting connection. 


\section{Wind tunnel tests}

The tests for the definition of the aerodynamic coefficients of the vehicles were performed in the high-speed test section of the Politecnico di Milano Wind Tunnel [11], where wind speeds up to $55 \mathrm{~m} / \mathrm{s}$ can be reached keeping the turbulence intensity around $0.2 \%$, which is lower than the limit value imposed by EN 14067-6 [12] equal to $2.5 \%$.

In order to satisfy the requirement of the EN 14067-6 standard on the blockage ratio (lower than $5 \%$ ), a $1 / 20$ scale model of a reduced trainset, composed by the locomotive and two freight wagons, was adopted.

The model of the freight wagon is made up of two parts: a flat-wagon and a container. The flat-wagon can be loaded with a $40-\mathrm{ft}$ container or with one or two 20 - $\mathrm{ft}$ containers. In order to measure separately the global forces acting on the overall vehicle (flat-wagon + container) and those acting on each container individually, two dynamometric balances were adopted for each wagon. The global aerodynamic load is measured by a balance set under the flat ground and linked to the wagon by means of a steel pole, directly connected to the model (Figure 5-left). The load on the single container is instead measured by a miniaturised balance (ATI balance) placed between the flat-wagon and the container (Figure 5-right).

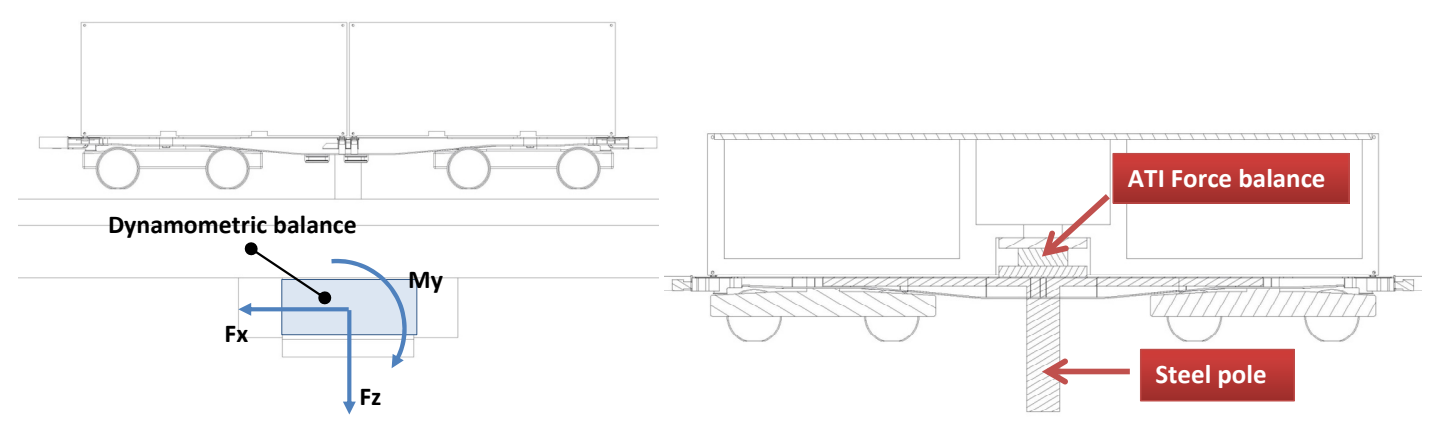

Figure 5: Layout for the measurement of the aerodynamic forces and moments: measurement of the global forces (left) and measurement of the forces on the container (right).

Eight different layouts were tested in order to verify the influence of vehicle composition on the aerodynamic forces acting on the wagons. Table 2 provides the list of the tested layouts, obtained combining different sizes and different distributions of empty and loaded wagons.

The flat ground scenario was investigated, where the vehicle is exposed to a practically uniform wind speed profile. This condition corresponds to the reference scenario in the TSI standard [13] and represents a flat terrain where no element capable of generating turbulence (buildings, hills or even trees) is present. In order to assure the uniformity of the wind profile the model is placed on a splitter table. The distance of the splitter table from the ground of the wind tunnel was set so that the model is not influenced by boundary layer. 


\begin{tabular}{|c|c|c|c|}
\hline Layout & Wagon 1 & Wagon 2 & Schematic \\
\hline 1 & $40 \mathrm{ft}$ container & $40 \mathrm{ft}$ container & 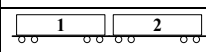 \\
\hline 2 & $40 \mathrm{ft}$ container & $120 \mathrm{ft}$ container & $\frac{15}{5000}$ \\
\hline 3 & $40 \mathrm{ft}$ container & $220 \mathrm{ft}$ containers & 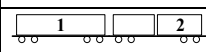 \\
\hline 4 & empty & $220 \mathrm{ft}$ containers & 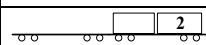 \\
\hline 5 & empty & $120 \mathrm{ft}$ container & ${ }_{0.00}^{2}$ \\
\hline 6 & empty & $40 \mathrm{ft}$ container & $000 \sigma_{00}^{2}$ \\
\hline 7 & $40 \mathrm{ft}$ container & empty & 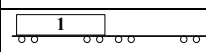 \\
\hline 8 & empty & empty & \\
\hline
\end{tabular}

Table 2: Description of the different trainset layouts tested in the wind tunnel.

The aerodynamic coefficients are calculated according to the EN 14067-6 standard. The reference system used for the definition of the aerodynamic forces is fixed to the wagon and its origin is coincident with the geometrical centre of the wagon, projected at the flat ground level. As shown in Figure 5, the $\mathrm{x}$-axis represents the longitudinal axis, while the $\mathrm{z}$-axis is perpendicular to the flat ground, downward directed. The y-axis is then oriented right-handed.

The aerodynamic coefficients measured on the entire trailing wagon are reported as a function of the wind angle of attack in Figure 6.
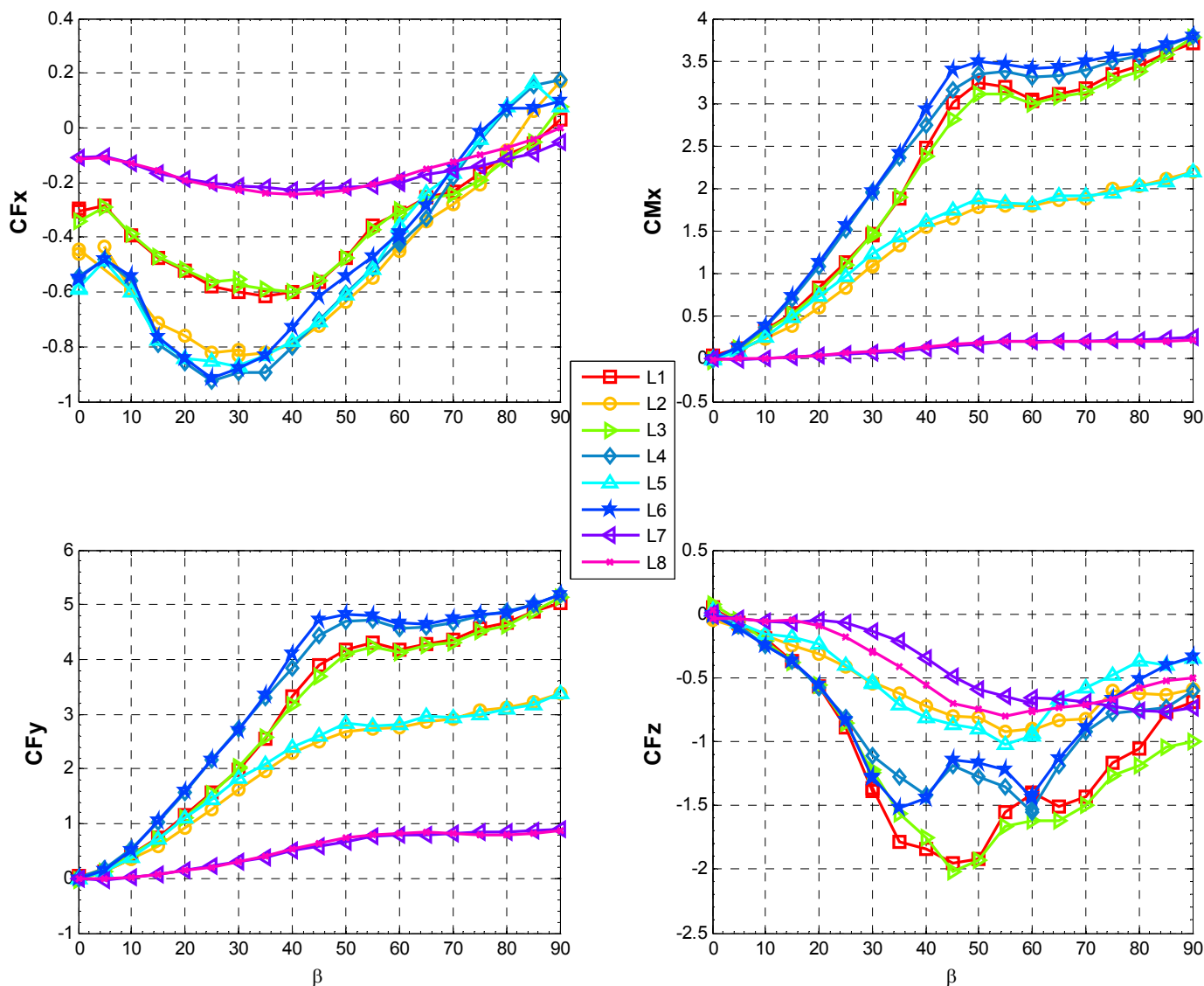

Figure 6: Aerodynamic coefficients of the trailing wagon for different trainset compositions. 
In this case, three groups can be distinguished since the trailing wagon was also tested in an intermediate load condition, where a single $20-\mathrm{ft}$ container was placed on the rear part of the wagon. In principle, this condition could be interesting because the container is much exposed to the wind, due to the large distance between the front surface of the container and the (possible) container placed on the first wagon. The magnitude of the coefficients is strictly related to the exposed surface. The maximum values of CFy and CMx coefficients are analogous to the one obtained for the first wagon. On the other hand, it is worth noticing that these coefficients are almost continuously increasing, with different slope, in the range of the angle of attack between $0^{\circ}$ and $90^{\circ}$, whereas, in the previous case, after they reach their maximum value around $50^{\circ}-55^{\circ}$, a small decrease is observed. Thus, the trailing wagon is subjected to larger forces (with respect to the first wagon) when the angle of attack is very large and it reaches values close to $90^{\circ}$. It is also important to observe that, considering just the layouts with the maximum surface (one $40 \mathrm{ft}$ container or $20 \mathrm{ft}$ containers), the maximum values of the coefficients are obtained for the layouts 6 and 4, which are characterised by a large gap in front of them, because the first vehicle is unloaded.

In Figure 7, the aerodynamic coefficients measured only on the container (40 ft long) are shown.
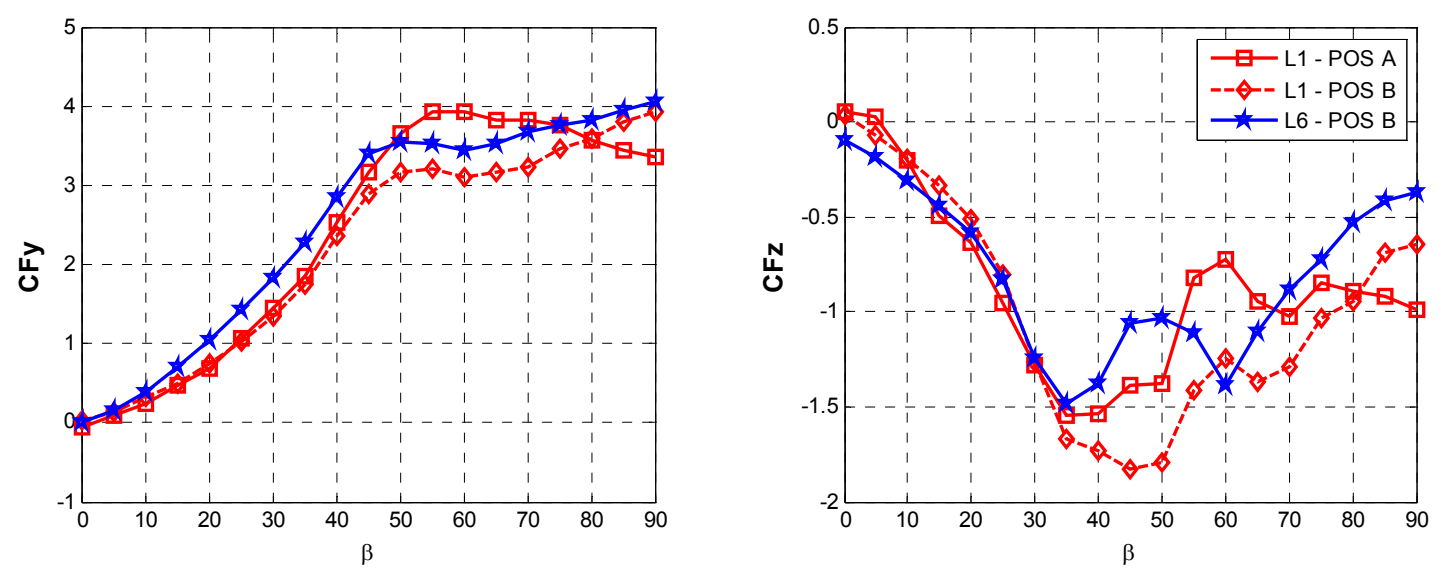

Figure 7: Aerodynamic coefficients of the single containers for different trainset compositions and positions.

The plots report the coefficients only for the two layouts 1 and 6, considering also the position where the container is located (Pos A stands for container on the leading wagon, Pos B stands for container on the trailing wagon). Since the major contribution to the lateral force is due to the wind force on the container and not on the flat-wagon, the trend of these coefficients are similar to those found in the previous analysis. In fact, also considering the container, the maximum value is reached with the container set on the first wagon (L1 - Pos A), but if we limit the analysis to the small angles, a container that follows an empty flat-wagon experiences the highest forces (L6 - Pos B). 


\section{Results}

In order to evaluate the risk of overturning of each freight wagon the Characteristic Wind Curves (CWC) are computed. The CWC represent the gust wind speed that leads the vehicle to a condition of quasi-overturning. This condition is evaluated, according to the TSI standard, in terms of vertical unloading of the windward wheels. In this paper the CWCs are calculated in tangent track, for the maximum vehicle speed $(\mathrm{V}=160 \mathrm{~km} / \mathrm{h})$, as a function of the wind velocity direction.

\subsection{Computational procedure of the characteristic wind curve}

The CWC of the freight wagons is computed using a stochastic approach, developed by the research group of the Politecnico di Milano [2,5]. This method is based on the numerical simulation of the dynamics of a vehicle subjected to the action of a real turbulent wind.

In the first step, the wind speed as a function of the time and the space is defined, according to a stochastic procedure, for specific values of turbulence intensity, integral length scale and mean wind speed $[2,5]$.

In the second step, starting from the aerodynamic coefficients experimentally evaluated, the corresponding time histories of the wind forces acting on a specific wagon are then calculated. In particular, for the simulations carried out in this paper, thanks to the aerodynamic coefficients separately measured both on the overall wagon and on the single container, the two contributions of the load acting on the flat-wagon and on the container are calculated and applied, considering a theoretical admittance function [14] for the container while a unitary function for the flatwagon.

The Lagrangian components of the aerodynamic forces are then computed and introduced into the non-linear equations describing the dynamics of the vehicle. Dynamic simulations of the vehicle subjected to the aerodynamic force time histories are computed increasing the wind speed until the unloaded index crossed the limit value of 0.9 :

$$
\frac{\Delta Q}{Q_{0}}=1-\frac{Q_{l, k}+Q_{t, k}}{2 Q_{0}}<0.9
$$

where $Q_{l, k}$ and $Q_{t, k}$ are the vertical forces acting on the unloaded wheels of the $k$-th bogie, which is the most critical, and $Q_{0}$ is the axle load.

The wind speed obtained defines the maximum allowed speed $U_{\text {lim }}$ referred to a given attack angle. Several simulations are repeated with different time histories of the wind (assuming the same turbulence index and spatial correlation) so that a distribution of maximum allowed speeds $U_{\text {lim }}$ is obtained. The characteristic wind speed $U_{c}$ is then identified assuming a normal distribution of $U_{\text {lim }}$ and the procedure is repeated for different angles of attack so that $U_{c}$ as function of $\beta$ can be obtained. This function is the Characteristic Wind Curve of the wagon. 


\subsection{Definition of the CWC}

The CWC were calculated only for the trailing vehicle, for the three most significant layouts, that are:

- layout 1 , a $40 \mathrm{ft}$ long container with another $40 \mathrm{ft}$ long container ahead. This layout is considered the reference one since the trainset should normally be in this condition;

- layout 6, a 40ft long container, without anything ahead;

- layout 5, a $20 \mathrm{ft}$ long container without a container on the leading vehicle.

The following analysis was carried out considering the containers in empty conditions. This option is obviously the most critical, but is for sure possible that the loading capacity is not fully used. Obviously increasing the total weight of the wagon the rollover possibility decreases, thus for each composition the CWC is essentially function of the hauled mass.

Assuming that the mass of the flat-wagon is equal to $12000 \mathrm{~kg}$, the values for the containers in empty conditions are reported in Table 3.

\begin{tabular}{|c|c|}
\hline Container size [ft] & Empty weight [kg] \\
\hline 20 & 2150 \\
\hline 40 & 3800 \\
\hline
\end{tabular}

Table 3: Mass of the containers in empty conditions.

Figure 8 shows a comparison between the CWC calculated for the three considered layouts.

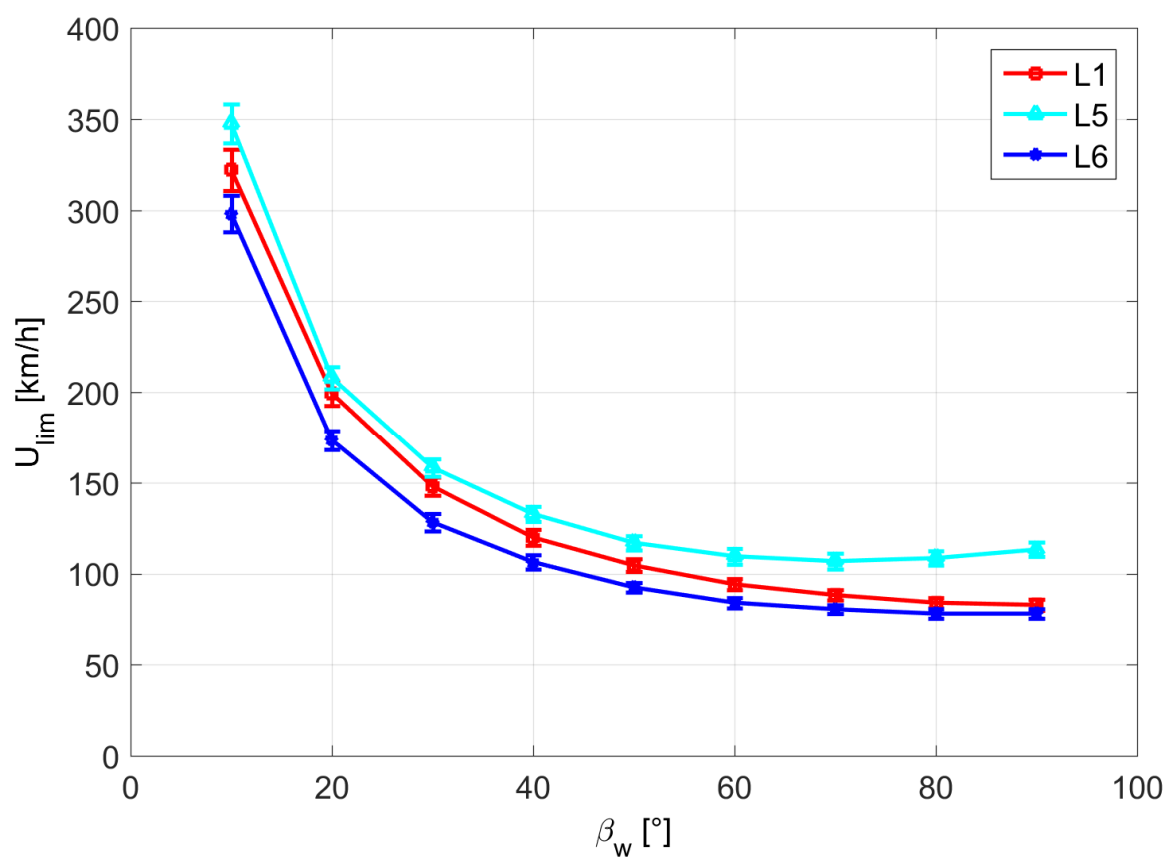

Figure 8: Comparison between the CWC of the trailing wagon with an empty container in different layouts. 
It is possible to see that the layout 6 (C6) is the most critical, being characterized by a lower limit wind speed (equal to $78 \mathrm{~km} / \mathrm{h}$ when the wind angle is equal to $80^{\circ}$ ): this result is in agreement with the trends found for the aerodynamic coefficients, especially those of rolling moment and lateral force that have a key role in the determination of the overturning risk. In fact, both these coefficients are greater than those measured with the other two considered layouts at all angles of attack.

On the other hand, the layout 5 is the least critical: this configuration is characterized by lower coefficients but also lower weight. Anyway, the reduction of the rolling moment coefficient is almost $50 \%$ while the reduction of mass is lower (about $40 \%$ ): this leads to a less critical condition in terms of overturning risk and a consequent higher CWC.

For each limit condition it was verified that the forces exchanged through the twistlock and corner casting connection were below the limit imposed in Table 1, ensuring that the most dangerous is situation is the rollover of the whole wagon and not the rollover of the container alone due to the breaking of the securing device.

\section{Conclusions}

In this paper the cross-wind effects on freight wagons were studied, in terms of the definition of the characteristic wind curves. Different operating conditions in terms of trainset layouts were analysed.

A multi-body model of the complete wagon was set-up, accounting for the flexibility of the twistlock - corner casting connection between the flat-wagon and the container. The force-deflection curves of the securing connection were obtained by means of a three-dimensional FE model.

Wind tunnel tests on a scaled model permitted to define the aerodynamic coefficients on both the flat-wagon and the container and it was proven that the most critical conditions corresponded to the case were the wagon is loaded with one or two empty containers. The absence of a container in the preceding wagon enhance the effects of crosswind.

The stochastic approach was used in order to define the CWC of the wagon, considering the most critical layouts.

It was proven that the cases were the trailing wagon was loaded with an empty $40-\mathrm{ft}$ container are the most critical. Of course this should be a very unlikely operating condition since the containers are generally loaded (even if not completely) but this result arise the problem of the succession of empty and loaded wagons which can determine very severe conditions. It was also verified that in the limit conditions the maximum forces exchanged through the twistlock - corner casting connection were below the limits imposed by the standard.

\section{References}

[1] Baker, C., Cheli, F., Orellano, A., Paradot, N., Proppe, C., Rocchi, D., Crosswind effects on road and rail vehicles. Vehicle System Dynamics 47(8): 983$1022,2009$. 
[2] Cheli, F., Corradi, R., Tomasini, G., Crosswind action on rail vehicles: A methodology for the estimation of the characteristic wind curves. Journal of Wind Engineering and Industrial Aerodynamics 104-106: 248-255, 2012.

[3] Rail Accident Investigation Branch (RAIB), Detachment of containers from freight wagons near Cheddington and Hardendale, 2009.

[4] S. Giappino, S. Melzi, G. Tomasini, M. Villani, "Experimental Study on the effect of Crosswind on a Container Train with Different Load Configurations", in J. Pombo, (Editor), "Proceedings of the Second International Conference on Railway Technology: Research, Development and Maintenance", Civil-Comp Press, Stirlingshire, UK, Paper 31, 2014. doi:10.4203/ccp.104.31

[5] Cheli, F., Corradi, R., Diana, G., Tomasini, G., A numerical-experimental approach to evaluate the aerodynamic effects on rail vehicle dynamics. Vehicle System Dynamics 41(Suppl.): 707-716, 2004.

[6] Bruni, S., Collina, A., Diana, G., Vanolo, P., Lateral dynamics of a railway vehicle in tangent track and curve: tests and simu-lation. Vehicle System Dynamics 33(Suppl.): 464-477, 2000.

[7] Braghin, F., Bruni, S., Diana, G., Experimental and numerical investigation on the derailment of a railway wheelset with solid axle. Vehicle System Dynamics 44(4): 305-325, 2006.

[8] Shen, Z.Y., Edrick, J.K., Elkins, J.A., A comparison of alternative creep force models for rail vehicle dynamic analysis, Proceedings of 8th IASVD Symposium, 591-605, 1983.

[9] Di Gialleonardo, E., Braghin, F., Bruni, S. The influence of track modelling options on the simulation of rail vehicle dynamics, Journal of Sound and Vibration, 331(19), 4246-4258, 2012.

[10] ISO 1997. ISO 3874: Series 1 freight containers - Handling and securing, 1997.

[11] Bocciolone, M., Cheli, F., Corradi, R., Muggiasca, S., Tomasini, G., Crosswind action on rail vehicles: Wind tunnel experi-mental analyses. Journal of Wind Engineering and Industrial Aerodynamics, 96(5): 584-610, 2008.

[12] CEN 2010. EN 14067: Railway applications - Aerodynamics - Part 6: Requirements and test procedures for cross wind assessment, 2010.

[13] TSI HS RST, 2008. Technical specification for interoperability relating to the 'rolling stock' sub-system of the trans-European high-speed rail system, 2008.

[14] Tomasini, G., Cheli, F., Admittance function to evaluate aerodynamic loads on vehicles: Experimental data and numerical model. Journal of Fluids and Structures 38: 92-106, 2013. 